\title{
Impact of Conflict Management Styles on Team Effectiveness in Textile Sector of Pakistan
}

\author{
Shamaila Gull (Corresponding author) \\ Lecturer (Business Studies), Institute of Business \& Information Technology (IBIT) \\ University of the Punjab, Quaid-e-Azam Campus, Lahore, Pakistan \\ Tel: 92-300-450-6757 E-mail: shamaila.gull@gmail.com \\ Habib-ur-Rehman \\ Graduated Student of MBIT, (Specialization in Marketing) Session 2009-11 \\ Institute of Business \& Information Technology (IBIT) \\ University of the Punjab, Quaid-e-Azam Campus, Lahore, Pakistan \\ Tel: 92-42-9923-0826 E-mail: habib_rehman40000@yahoo.com
}

Syeda Farheen Batul Zaidi

Lecturer (Business Studies), Institute of Business \& Information Technology (IBIT)

University of the Punjab, Quaid-e-Azam Campus, Lahore, Pakistan

Tel: 92-301-441-0755Ｅ-mail: farheen.zaidi@ibitpu.edu.pk

Received: July 18, 2011

doi:10.5539/ijbm.v7n3p219
Accepted: August 29, 2011

Published: February 1, 2012

URL: http://dx.doi.org/10.5539/ijbm.v7n3p219

\begin{abstract}
The rationale of this study is to catch sight of causal relationship between conflict management styles and team effectiveness and elucidate particular style's impact on team effectiveness and give management insight into particular style that can either stir up team's performance or hamper its progress.Apart from examining correlation between conflict management styles and team effectiveness, diverse factors like gender, designation, income level and age were also scrutinized to unearth factors which ostensibly propel an individual to pursue a specific conflict management style. Internationally devised questionnaire was deployed to ascertain numerical score of both qualitative variables. Research was conducted on basis of random sampling. Total sample size of research is 220. Respondents include employees working in various textile firms operating in Pakistan. Statistical tests serving purpose of this study are Pearson's Chi-Square Test, Yates Chi-Square Test, Crammer's coefficient of contingency, Pearson Coefficient of mean-squared contingency. Data analysis also includes regression analysis of data, correlation coefficients and development of linear regression models. The final analysis revealed moderate effect of conflict management style on team effectiveness. Collaborative and Accommodating style of team effectiveness found to be highly positively associated with team effectiveness. Competing style demonstrated insignificance relation to team effectiveness. Compromising style revealed negative association while avoiding style exhibited high negative correlation with team effectiveness. Age, Gender, Income level and Designation were not found to have an influence on particular conflict management style being pursued by individuals.
\end{abstract}

Keywords: Conflict, Team, Conflict management style, Team effectiveness, Textile sector

\section{Introduction}

Conflict is undoubtedly inevitable constituent of any team keeping in view of the fact that team is composed of individuals with varying attitudes, beliefs and objectives. On one side, conflict can perturb team's spirit, detriment cooperation level and plummet motivation level but on contrary conflict can manufacture lucrative ideas. It can expand the awareness of a particular situation, escalate cooperation among the group members, 
sharpening their focus on goals and people try to learn about each other and develop skills that are necessary to be a good team player.

Aforementioned facts illuminates that conflict is neither dreadful nor virtuous but depends on personal alacrity to deal it with finesse. Researchers have uncovered distinctive conflict management styles which are cooperation, accommodation, competition, avoidance and compromising.

The research attempted to unfold any relation of prescribed conflict management styles to team effectiveness in various textile firms which can be of elevated essence to employees for pursuing particular conflict management style in a conflict situation. Apart from examining propensity of relationship between conflict management styles and team effectiveness, diverse factors like gender, designation, income level and age were separately scrutinized to unearth their significance in propelling a particular conflict management styles, which they failed to showcase in our study.

\section{Literature Review}

Team consist of people with different ideas, values, beliefs and objectives so if clash occurs in those concerns of team member's conflict is likely to creep in. There are few processes, which can potentially influence the outcome of conflict situation. "The orientation of personnel involved in any sort of conflict towards winning or losing can cause destruction to any situation, like wise assistance and courtesy can prove to be constructive elements in conflicting circumstances"(Rubin, 1977).

The tactic for dispensing social justice to the parties engaged in conflict is immensely important. "No one should be deprived of justice as it can harm one's feeling and hinder the progress of any group or institution". (Jehn, 1996).

"Factors such as Fear, expectations, different knowledge, bad communication, stress and misunderstanding can prelude a conflict. This is followed by a triggering event which can stimulate emotions and feelings of people in a group". (Krammer, 1991).

Conflict is seen from two perspectives; one is good and other is bad. Those who view conflicts as bad argue that every organization or group is composed of people who are gathered to complement and support each other. "It is no surprise that today's managers and employees still overwhelmingly view conflict as negative and something to be avoided or resolved as soon as possible" (Stone, 1995).

The people who perceives conflict as a positive element argues that the most important factor in survival of any organization is change, and change comes through conflict. "Indeed, growing evidence suggests that conflict may bebeneficial to team performance. Suppressing conflict could reduce creativity, innovation, performance, quality of decisions, and communication between group's members" (Oldham, 1996).

The clash of interest causes interpersonal conflict to creep in the minds of people. "Interpersonal conflict is conflict arising among the members of same organization and mainly due to difference in goals, objectives and incentives of people. " (Vliert, 1997)

"Fred tanner describes conflict management as a process to mitigate and avoid risk without solving it (tanner, 2000)" Tanner does not perceive conflict management as a solution to a problem rather he views it as avoidance of risk. "Dr. Holmes described conflict management as a systematic process to find a mutually satisfying outcome for the conflicted parties (Dr. Holmes, 2010). But usually when disputes arise in different parties or persons in a team it is very hard to satisfy both parties equally, one of the parties might well be left aggrieved with the outcome of the conflict.

Team effectiveness is the ability of the team to meet the goals and objectives of the company. Several models have been given by the researchers over the years to measure the team effectiveness. "Michael Lombardo and Robert Eichinger developed the famous T7 Model in 1995 to represent the factors that measure the team effectiveness. The internal factors are Thrust, Trust, Talent, Teaming skill, Task Skills and external factors are Team-Leader fit, Team support from the organization." (Keneth, 2009)

"Thrust clarity means the clearness of goal and vision in the minds of team members. Objectives and goals should be communicated in such a way that no ambiguity is left in the mind of people about the purposes. Thrust commitment shows level of commitment of team members to achieve that goal." (Moye, 2004)

"In 1977 Plovnick and Fry proposed a model for team effectiveness known as GRPI model. GRPI stands for Goals, Roles, Processes, and Interpersonal Relationships.” (Jehn K., 2001)

A study on conflict management styles and team effectiveness view conflict management as a team phenomenon. The study take team identity as a moderating variable and see how task interdependence relates to conflict 
management style (cooperative versus competitive) and how it leads to team effectiveness. (Latham, 1977)

So keeping in view of team's vital role in present day business surroundings, this study accentuates apt and judicious conflict management style for employees to pursue while indulged in conflict situation to accomplish unprecedented success.

\section{Research Methodology}

Purpose of study is to spot causal relationship of conflict management styles which are collaborative, competing, accommodating, compromising and avoiding, to team effectiveness. And also vieweach particular style's impact on team effectiveness and give management and other employee's insight into styles that can augment or detriment performance of a team.

Sample size of this research was 220 employees of either manager or officer level to ensure respondents suitability to research. They all belong to various different textile firms currently operating in Pakistan. Questionnaire was picked as a tool to collect primary data from respondents.

The questionnaire was composed of two sections, one assessed the conflict management style pursued by respondent and other section ascertained score of team effectiveness. Section I of questionnaire had questions which were precisely measuring conflict management style by giving points from 1-5 on each dimension of variable. The maximum cumulative score of dimensions of a conflict management style was taken as respondents most preferred style, while Section II of questionnaire was measuring team effectiveness as a whole with giving 1-5 points to each statement.

Total score obtained from section II of questionnaire either lies in three levels of team effectiveness low, medium, or high. Anything between 27 to 63 is rated as low team effectiveness. 63 to 99 is the range for medium team effectiveness and 99 to 135 is range for high team effectiveness. The total range for team effectiveness was 27-135 since section II contained total 27 questions, and minimum possible score could have been 27 and maximum 135.

After ascertaining opted conflict management style and team effectiveness score of each respondent, rigorous statistical test were deployed in order to gauge intensity of relationship between variables. Statistical tests serving purpose of this study are Pearson's Chi-Square Test, Yates Chi-Square Test, Crammer's coefficient of contingency, Pearson Coefficient of mean-squared contingency. MS Excel was used to help in regression analysis of data, correlation coefficients and development of linear regression models.

\section{Results}

\subsection{Conflict Management Styles and Team Effectiveness}

The prime reason to undertake this study is to uncover degree of relationship between conflict management styles and team effectiveness.

Linear relationship between conflict management style and team effectiveness in table 1 means that if we move up in table from avoiding to collaborating style, team effectiveness move from low to high. Collaborating and accommodating styles are capturing highest percentage points in high team effectiveness. Competing and compromising are in medium team effectiveness range and avoiding style scored highest percentage points in low team effectiveness.

Figure 1 illustrates the relationship between conflict management styles and team effectiveness at a glance. Percentages have been used to describe the relationship in a meaningful way.

Hypothesis 1:

H0: Null Hypothesis: There is no impact of conflict management style on team effectiveness

Ha: Alternate Hypothesis: There is an impact of conflict management style on team effectiveness

In Table 2, since the computed chi-squares value (51.10) is greater then the chi-square table value (15.5), so we reject our null hypothesis and accept our alternative hypothesis, which is, the two variables are not independent, and they are associated. Therefore, there is an impact of conflict management style on team effectiveness. After describing overall impact of conflict management styles on team effectiveness, individual effect of a particular conflict management style on team effectiveness was also tested.

\subsubsection{Collaborating Style and Team Effectiveness}

In figure 2, collaborative style of conflict management was found to be highly associative with team effectiveness as majority of respondents pursuing collaborative style scored high on team effectiveness. 
Positive value of slope in equation above indicates a positive relation between collaborative style and team effectiveness and apart from that correlation coefficient $\mathbf{R}^{\mathbf{2}}=\mathbf{0 . 9 7 9 6}$ also indicates high positive association between collaborative style and team effectiveness.

\subsubsection{Accommodating Style and Team Effectiveness}

Accommodating style of conflict management in figure 3also depicted positively relation with team effectiveness as majority of respondents pursuing accommodating style scored high on team effectiveness. Positive value of slope in equation above indicates a positive relation between accommodating style and team effectiveness. The correlation coefficient $\mathbf{R}^{2}=\mathbf{0 . 8 4 5 9}$, also indicates high positive association between accommodating style and team effectiveness.

\subsubsection{Competing Style and Team Effectiveness}

Competing style of conflict management in figure 4failed to demonstrate any significant impact on team effectiveness.Low value of slope in equation above indicates a no significance relation between competing style and team effectiveness and the correlation coefficient $\mathbf{R}^{2}=\mathbf{0 . 1 9 6 7}$, also failed to indicate any significant association between competing style and team effectiveness.

\subsubsection{Compromising Style and Team Effectiveness}

Respondents pursuing compromising style of conflict management depicted negative influence of compromising style on team effectiveness. Negative value of slope in equation mentioned in figure 5 above indicates negative relation between Compromising style and team effectiveness and the correlation coefficient $\mathbf{R}^{2}=\mathbf{- . 5 7 1 4}$, also indicates negative association between Compromising style and team effectiveness.

\subsubsection{Avoiding Style and Team Effectiveness}

Avoiding style of conflict management portrayed highly negative influence on team effectiveness as majority of respondents pursuing avoiding style scored low on team effectiveness. Negative value of slope in equation, mentioned in figure 6, indicates negative relation between Avoiding style and team effectiveness. The correlation coefficient $\mathbf{R}^{2}=\mathbf{- . 9 9 8 5}$, also indicates highly negative association between Avoiding style and team effectiveness.

\subsection{Gender and Conflict Management Styles}

\section{Hypothesis 2:}

H0: Null Hypothesis: There is no impact of Gender on conflict management style being followed.

Ha: Alternate Hypothesis: There is an impact of Gender on conflict management style being followed.

The chi-square value for the data is 5.86 . The value of chi-square in the table against,

Degree of freedom $=(\mathrm{r}-1)(\mathrm{c}-1)=(2-1)(5-1)=1 * 4=4, \quad$ and

Level of confidence at $5 \%$ is, $\quad \chi^{2}$ (table) $=9.48$

$$
\begin{aligned}
& \chi^{2}>\chi^{2} \text { (table) } \\
& 5.86>9.48 \text { (false) }
\end{aligned}
$$

We fail to reject Ho

Computed chi-squares value (5.86) is less than the chi-square table value (15.5), we fail to reject null hypothesis, which means, the two variables are independent. Gender has no influence on conflict management style being followed. Table 3 shows the same result as mentioned here.

\subsection{Employee Designation and Conflict management style:}

Employees who filled questionnaires belonged to different departments of textile firms such as marketing, finance, yarn procurement, planning and folding section. The main categories in which employees are divided are either

1) Manager level employee such as Manager and assistant manager, or

2) Officer level employees who mainly assist their immediate supervisor, who may be assistant manager or manager.

According to Table 4, majority of sample of manager level employees were using accommodating style of conflict management, whereas majority of officer level employees were found to be using collaborative style of conflict management. Compromising style came across as least preferred style for both, manager and officer 
level employees.

Hypothesis 3:

$H_{0}$ : Null Hypothesis: There is no impact of designation on conflict management style being followed.

$H_{a}$ : Alternate Hypothesis: There is an impact of designation on conflict management style being followed.

The chi-square value for the data is 1.14 , which is actually a very low value, which means that there is no deviation in the designations. The value of chi-square in the table against,

Degree of freedom $=(r-1)(c-1)=(2-1)(5-1)=1 * 4=4, \quad$ and

Level of confidence at $5 \%$ is, $\quad \chi^{2}$ (table) $=9.48$

$$
\begin{array}{lr}
\chi 2 & >\chi 2 \text { (table) } \\
1.14>9.48 \text { (false) }
\end{array}
$$

We fail to reject Ho

Computed chi-squares value (1.14) is less then the chi-square table value (15.5) so we fail to reject our null hypothesis, which means, the two variables are independent. Designation has no influence on conflict management style being followed.

\subsection{Age and Conflict management style}

Table 5 clearly shows that majority of our respondents is between age bracket of 20-30 years, which are 130 in total. Between ages of 30-40, there are 69 respondents and remaining 21 respondents are of age 40 and above.

Table 6 shows the cross tabulation of age and conflict management styles along with their respective percentages and it is evident that majority of the respondents adopt accomodating style irrespective of their age group.

Hypothesis 4:

$H_{0}$ : Null Hypothesis: There is no impact of age on conflict management style being followed.

$H_{a}$ : Alternate Hypothesis: There is an impact of age on conflict management style being followed.

The chi-square value for the data is 5.16 and the value of chi-square in the table is computed below,

Degree of freedom $=(r-1)(c-1)=(3-1)(5-1)=2 * 4=8, \quad$ and

Level of confidence at $5 \%$ is, $\quad \chi^{2}($ table $)=15.5$

$$
\chi^{2}>\chi^{2}(\text { table })
$$

$5.16>15.5$ (false)

We fail to reject Ho

Computed chi-squares value (5.16) is less then the chi-square table value (15.5), we fail to reject null hypothesis, which means, the two variables are independent. Age has no influence on conflict management style being followed.

4.5 Income Level and Conflict management style

According to table 7, majority of respondents are between income level of 20-40 thousand, which is almost half of total sample. The respondents enjoying income level more than 60 thousand are generally manager level or senior level officer grade employees.

Table 8 shows the cross tabulation of income level and conflict management styles along with their respective percentages and it is evident that majority of the respondents adopt accommodating and collaborating styles irrespective of their income level.

Hypothesis 5:

$H_{0}$ : Null Hypothesis: There is no impact of Income level on conflict management style being followed.

$H_{a}$ : Alternate Hypothesis: There is an impact of Income level on conflict management style being followed.

The chi-square value for the data is 3.08 and the value of chi-square in the table is computed below,

Degree of freedom $=(r-1)(c-1)=(4-1)(5-1)=3 * 4=12, \quad$ and

Level of confidence at $5 \%$ is,

$$
\chi 2(\text { table })=21.02
$$




$$
\begin{aligned}
& \chi^{2}>\quad \chi^{2} \text { (table) } \\
& 3.08>21.02 \text { (false) } \\
& \text { We fail to reject Ho }
\end{aligned}
$$

Since the computed chi-squares value (3.08) is less then the chi-square table value (21.02) so we fail to reject our null hypothesis, which means, the two variables are independent. Income Level has no influence on conflict management style being followed.

\section{Key Findings}

The most important finding of this research is that "conflict management style has an impact on team effectiveness". This particular statement was our first hypothesis of study which demonstrated that five styles of conflict management Competing, Compromising, Avoiding, Accommodating and Cooperative have collectively an impact on team effectiveness. Later on, further analysis of cross tabulation revealed that conflict management styles have medium impact on team effectiveness.

$>\quad$ Collaborative style of team effectiveness found to be highly positively associated with team effectiveness as majority of respondents pursuing collaborative style scored high on team effectiveness.

Accommodating style also depicted positive correlation with team effectiveness.

$>\quad$ Competing style showed mixed trend with team effectiveness, as a result there wasn't any significant relation was found between competing style and team effectiveness.

$>\quad$ Compromising style revealed negative association with team effectiveness and avoiding style exhibited high negative correlation with team effectiveness.

$>\quad$ Age, Gender, Income level and Designation were not found to have an influence on particular conflict management style being followed by any person.

\section{Conclusion}

Conflict is indispensible in any team or work environment. The tactic to deal with conflicted situation keeps on varying from individual to individual. An individual's expediency and judiciousness in a conflict situation can open up new horizons of flabbergasting ideas to achieve excellence in business. There has been heated debate about which conflict management style to pursue in conflict and weighing scale seems titling more towards collaboration rather than competition asavowed by this study, which indicates that it is better to be collaborative and accommodating with your colleagues in order to achieve high team effectiveness, since collaborative and accommodating styles of team effectiveness boast up level of trust among members, establishes a sense of harmony and creates an enjoyable work place which facilitates employees to work freely and creatively to achieve high performance and efficiency for the team. Also employees must be wary of compromising and avoiding style as they give way to many misunderstandings among team members which keeps on piling up with the passage of time, hence employees become subject to frustration and de-motivation which ruins team performance and effectiveness as a consequence.

\section{References}

Alper, S. D. (2000). Conflict management, efficacy and performance in work teams.

Barker, J. D. (1988). Conflict Approaches of Effective and Ineffective Managers.

Bergmann, T. J. (1997). Diagnosing whether an organization is truly ready to empower work teams. Human Resource Planning, 38-47.

Bies, R. (1987). The Predicament of Injustice: The Management of Moral Outrage. (Vol. vol. 9). Greenwich, CT: JAI Press.

De Meuse, K. P. (2009). Construct validation of Lominger T7 Model of team effectiveness. Minneapolis, MN: Lominger International .

Deutsch, M. (1973). The Resolution of Conflict.

Jehn, K. (2001). The dynamic nature of conflict: A longitudinal study of intragroup conflict and. Academy of Management Journal.

jehn, K. A. (1997). A qualitative analysis of conflict types and dimensions in organizational groups.

Jehn, K., \&. (2001). The dynamic nature of conflict: A longitudinal study of intragroup conflict and. Academy of Management Journal. 
Johnson, D. M. (1981). Effects of cooperative, competitive, and individualistic goal structures on achievement. Psychological Bulletin, 47-62. http://dx.doi.org/10.1037/0033-2909.89.1.47

Katzenbach, J. R. (1993). The wisdom of teams: Creating the high-performance organization.

Kirkman, B. L. (2008). Exporting" teams:Enhancing the implementation and effectiveness of work teams in global affiliates. Organizational Dynamics, 12-39.

Kramer, R. (1991). Intergroup relations and organizational dilemmas. Research in organizational behavior, 191-228.

Kramer, R. (1991). Intergroup relations and organizational dilemmas. Research in organizational behavior, 191-228.

Latham, G. P. (1977). Goal setting: A motivational technique that works. Organizational Dynamics, 68-80.

Lencioni, P. (2002). The five dysfunctions of a team. A leadership fable.

Moye, N. (2004). Information sharing and group conflict: Going beyond decision making to understand the effects of information sharing on group performance. The International Journal of Conflict, 381-410.

Moye, N. (2004). Information sharing and group conflict: Going beyond decision making to understand the effects of information sharing on group performance. The International Journal of Conflict, 381-410.

Naquin, C. E. (2009). The team halo effect: Why teams are not blamed for their failures. Journal of Applied Psychology, 332-340.

Oldham, G. R. (1996). Employee creativity: Personal and contextual factors at work. Academy of Management Journal, 607-634. http://dx.doi.org/10.2307/256657

Rubin, I. M. (1977). Task oriented team development.

Schopler, J. H. (1996). Interorganizational groups: Origins, structure and outcomes. pp. 702-713.

Simons, T. (2005). Task conflict and relationship conflict in top management teams: The pivotal role of intragroup trust. Journal of Applied Psychology, 102-111.

Tjosvold, D. (1993). Learning to manage conflict: Getting people to work together productively.

Tjosvold, D. H. (2003). Conflict values and team relationships. Journal of Organizational Behavior, 69-88. http://dx.doi.org/10.1002/job.180

Wilmot, W. W. (2001). Interpersonal conflict. New York: McGraw-Hill.

Table 1. Bivariate Table for Conflict Management Styles and Team Effectiveness with Linear Regression Line

\begin{tabular}{|c|c|c|c|c|c|c|c|}
\hline \multirow{2}{*}{$\begin{array}{l}\text { Conflict } \\
\text { Management Styles }\end{array}$} & \multicolumn{5}{|c|}{ Team Effectiveness } & \multirow[b]{2}{*}{$\%$} & \multirow[b]{2}{*}{ Total } \\
\hline & Low & $\%$ & Medium & $\%$ & High & & \\
\hline Collaborating & 6 & $10 \%$ & 18 & $29 \%$ & 38 & $61 \%$ & 62 \\
\hline Accommodating & 11 & $19 \%$ & 14 & $24 \%$ & 34 & & 59 \\
\hline Competing & 8 & $22 \%$ & 17 & & 12 & $32 \%$ & 37 \\
\hline Compromising & 11 & $41 \%$ & 13 & $48 \%$ & 3 & $11 \%$ & 27 \\
\hline \multirow[t]{2}{*}{ Avoiding } & 19 & $54 \%$ & & $34 \%$ & 4 & $11 \%$ & 35 \\
\hline & 55 & & 74 & & 91 & & 220 \\
\hline
\end{tabular}


Table 2.

\begin{tabular}{|c|c|c|}
\hline Pearson Chi-Square Value & $\chi^{2}$ & 5 L10 \\
\hline Degree of freedom & $(\mathrm{r}-1)(\mathrm{c}-1)$ & 8 \\
\hline Level of confidence & $\mathrm{a}$ & $5 \%$ \\
\hline Chi-Square Table Value & $\chi^{2(\text { table })}$ & 15.5 \\
\hline
\end{tabular}

Table 3. Bivariate table for Gender and Conflict management style

\begin{tabular}{|l|l|l|l|l|l|l|l|l|l|l|l|}
\hline Gender & \multicolumn{2}{l|}{ Conflict Management Styles } \\
\hline & Accommodating & $\%$ & Avoiding & $\%$ & Collaborating & $\%$ & Competing & $\%$ & Comproising & $\%$ & Total \\
\hline Female & 23 & $\mathbf{3 2}$ & 11 & $\mathbf{1 5}$ & 13 & $\mathbf{1 8}$ & 14 & $\mathbf{1 9}$ & 11 & $\mathbf{1 5}$ & 72 \\
\hline Male & 36 & $\mathbf{2 4}$ & 24 & $\mathbf{1 6}$ & 49 & $\mathbf{3 3}$ & 23 & $\mathbf{1 6}$ & 16 & $\mathbf{1 1}$ & 148 \\
\hline Total & $\mathbf{5 9}$ & & $\mathbf{3 5}$ & & $\mathbf{6 2}$ & & $\mathbf{3 7}$ & & $\mathbf{2 7}$ & & $\mathbf{2 2 0}$ \\
\hline
\end{tabular}

Table 4. Bivariate table for Employee Designation and Conflict management style

\begin{tabular}{|l|l|l|l|l|l|l|l|l|l|l|l|}
\hline & \multicolumn{2}{l|}{ Conflict Manegement Styles } \\
\hline Designation & Accommodating & $\%$ & Avoiding & $\%$ & Collaborating & $\%$ & Competing & $\%$ & Compromising & $\%$ & $\begin{array}{l}\text { Grand } \\
\text { Total }\end{array}$ \\
\hline Manager & 16 & 30 & 10 & 19 & 13 & 24 & 8 & 15 & 7 & 13 & 54 \\
\hline Officer & 43 & 26 & 25 & 15 & 49 & 30 & 29 & 17 & 20 & 12 & 166 \\
\hline Total & 59 & & 35 & & 62 & & 37 & & 27 & & 220 \\
\hline
\end{tabular}

Table 5. Univariate table for Age

\begin{tabular}{|l|l|}
\hline Age & Total \\
\hline $\mathbf{2 0 - 3 0}$ & 130 \\
\hline $\mathbf{3 0 - 4 0}$ & 69 \\
\hline $\mathbf{4 0}+$ & 21 \\
\hline Total & $\mathbf{2 2 0}$ \\
\hline
\end{tabular}

Table 6. Bivariate table for Age and Conflict Management Styles

\begin{tabular}{|l|l|l|l|l|l|l|l|l|l|l|l|}
\hline & \multicolumn{9}{l|}{ Conflict Manegement Styles } \\
\hline Age & Accommodating & $\%$ & Avoiding & $\%$ & Collaborating & $\%$ & Competing & $\%$ & Compromising & $\%$ & $\begin{array}{l}\text { Grand } \\
\text { Total }\end{array}$ \\
\hline $20-30$ & 33 & $\mathbf{2 5}$ & 22 & $\mathbf{1 7}$ & 39 & $\mathbf{3 0}$ & 20 & $\mathbf{1 5}$ & 16 & $\mathbf{1 2}$ & 130 \\
\hline $30-40$ & 19 & $\mathbf{2 8}$ & 8 & $\mathbf{1 2}$ & 22 & $\mathbf{3 2}$ & 12 & $\mathbf{1 7}$ & 8 & $\mathbf{1 2}$ & 69 \\
\hline $40+$ & 7 & $\mathbf{3 3}$ & 5 & $\mathbf{2 4}$ & 1 & $\mathbf{5}$ & 5 & $\mathbf{2 4}$ & 3 & $\mathbf{1 4}$ & 21 \\
\hline Total & $\mathbf{5 9}$ & & $\mathbf{3 5}$ & & $\mathbf{6 2}$ & & $\mathbf{3 7}$ & & $\mathbf{2 7}$ & & $\mathbf{2 2 0}$ \\
\hline
\end{tabular}


Table 7. Univariate table for Income Level

\begin{tabular}{|l|l|}
\hline Income Level(Thousands) & Gramd Total \\
\hline$<20$ & 31 \\
\hline $20-40$ & 107 \\
\hline $40-60$ & 53 \\
\hline $60+$ & 29 \\
\hline Total & 220 \\
\hline
\end{tabular}

Table 8. Bivariate Table for Income Level and Conflict Management Styles

\begin{tabular}{|c|c|c|c|c|c|c|c|c|c|c|c|}
\hline & Conflict Manege & nent & Styles & & & & & & & & \\
\hline $\begin{array}{l}\text { Income } \\
\text { Level }\end{array}$ & Accommodating & $\%$ & Avoiding & $\%$ & Collaborating & $\%$ & Competing & $\%$ & Compromising & $\%$ & $\begin{array}{l}\text { Grand } \\
\text { Total }\end{array}$ \\
\hline$<20000$ & 6 & 19 & 4 & 13 & 12 & 39 & 4 & 13 & 5 & 16 & 31 \\
\hline $20-40$ & 30 & 28 & 18 & 17 & 29 & 27 & 19 & 18 & 11 & 10 & 107 \\
\hline $40-60$ & 15 & 28 & 7 & 13 & 16 & 30 & 8 & 15 & 7 & 13 & 53 \\
\hline $60+$ & 8 & 28 & 6 & 21 & 5 & 17 & 6 & 21 & 4 & 14 & 29 \\
\hline Total & 59 & & 35 & & 62 & & 37 & & 27 & & 220 \\
\hline
\end{tabular}

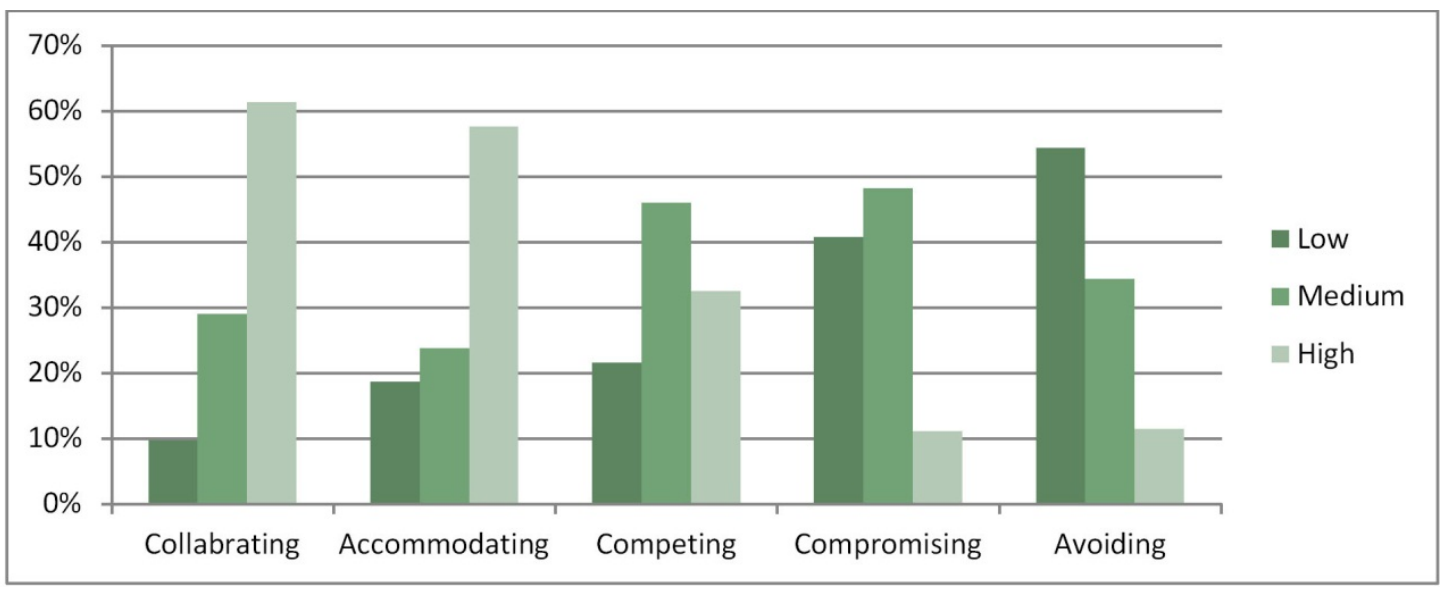

Figure 1. Conflict Management Styles and Team Effectiveness

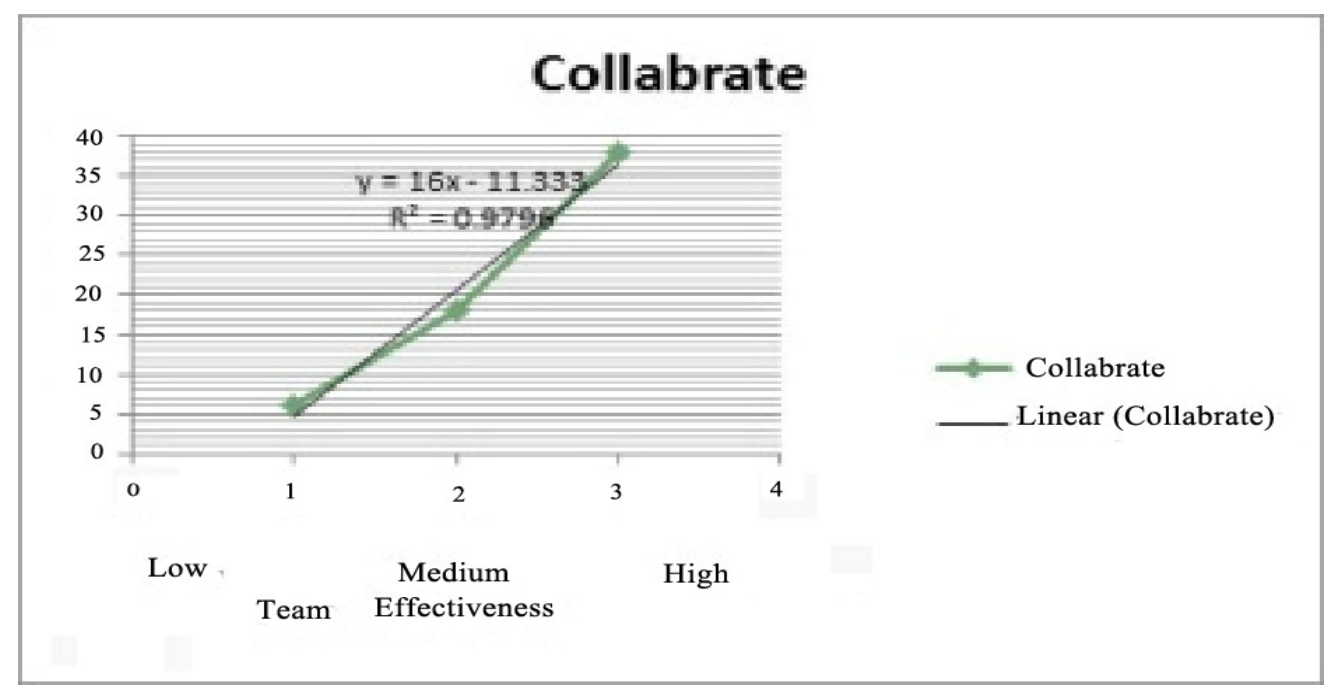

Figure 2. Collaborating Style and Team Effectiveness 


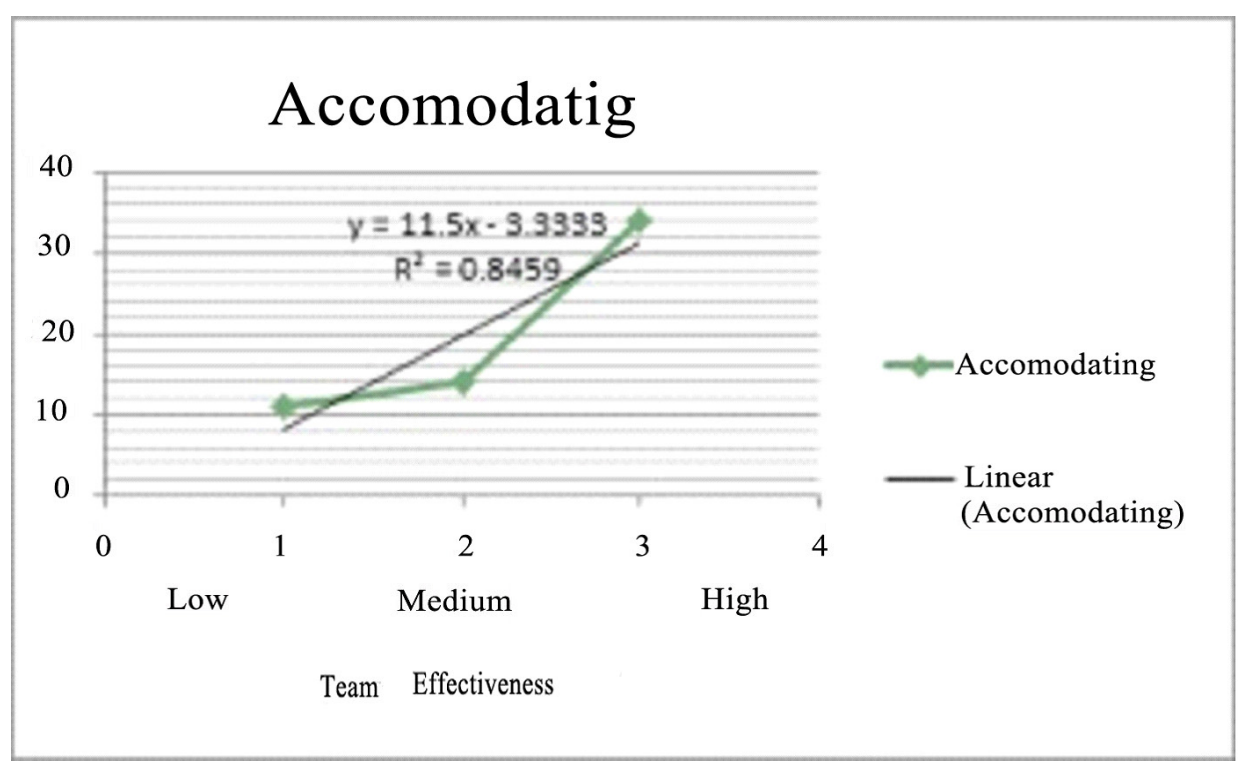

Figure 3. Accommodating Style and Team Effectiveness

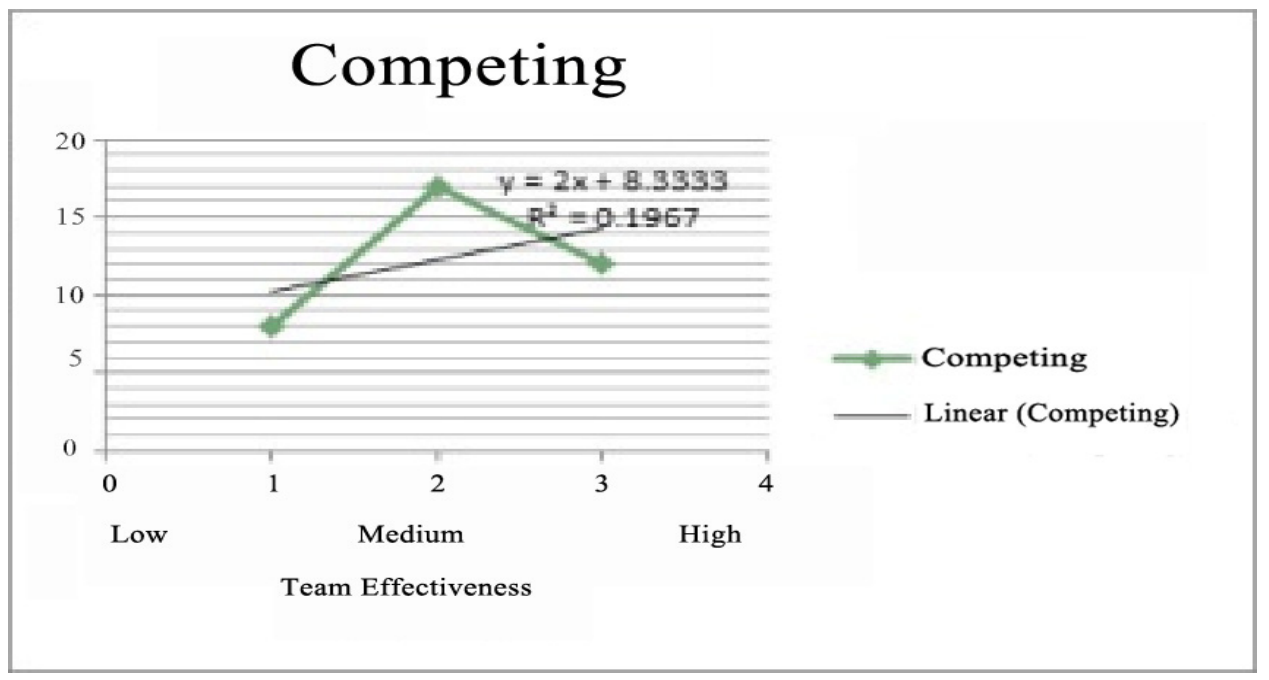

Figure 4. Competing Style and Team Effectiveness

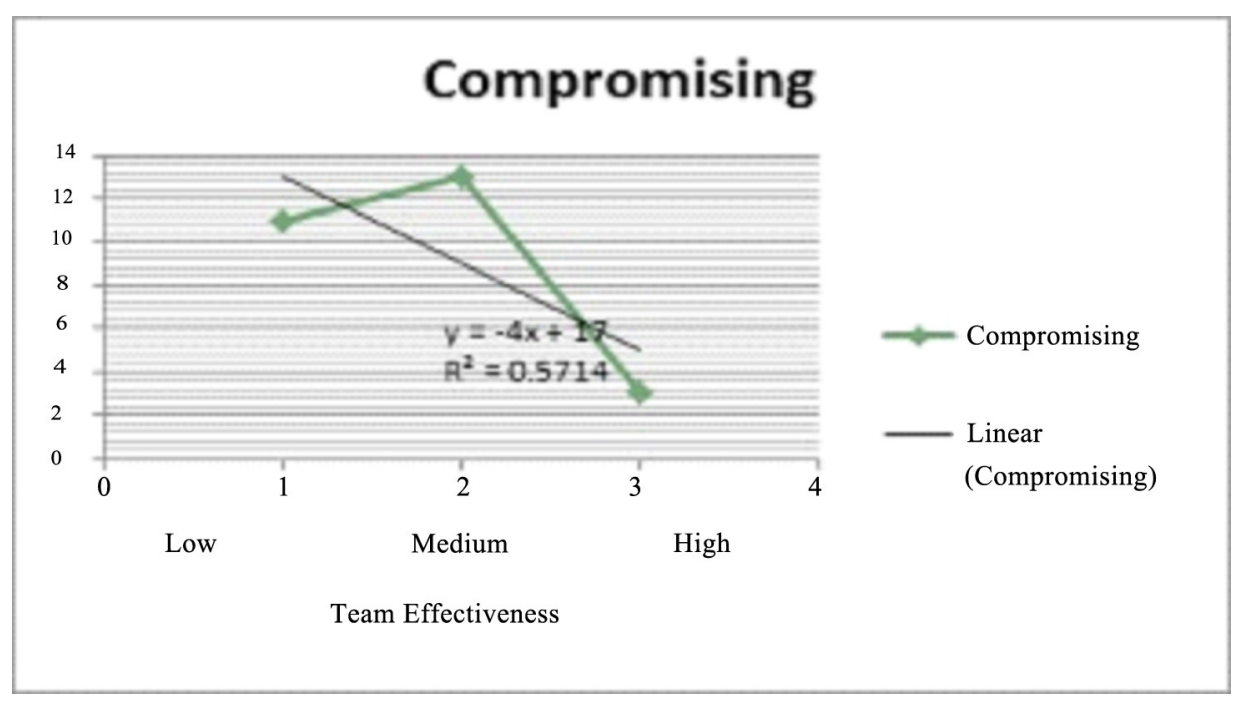

Figure 5. Compromising Style and Team Effectiveness 


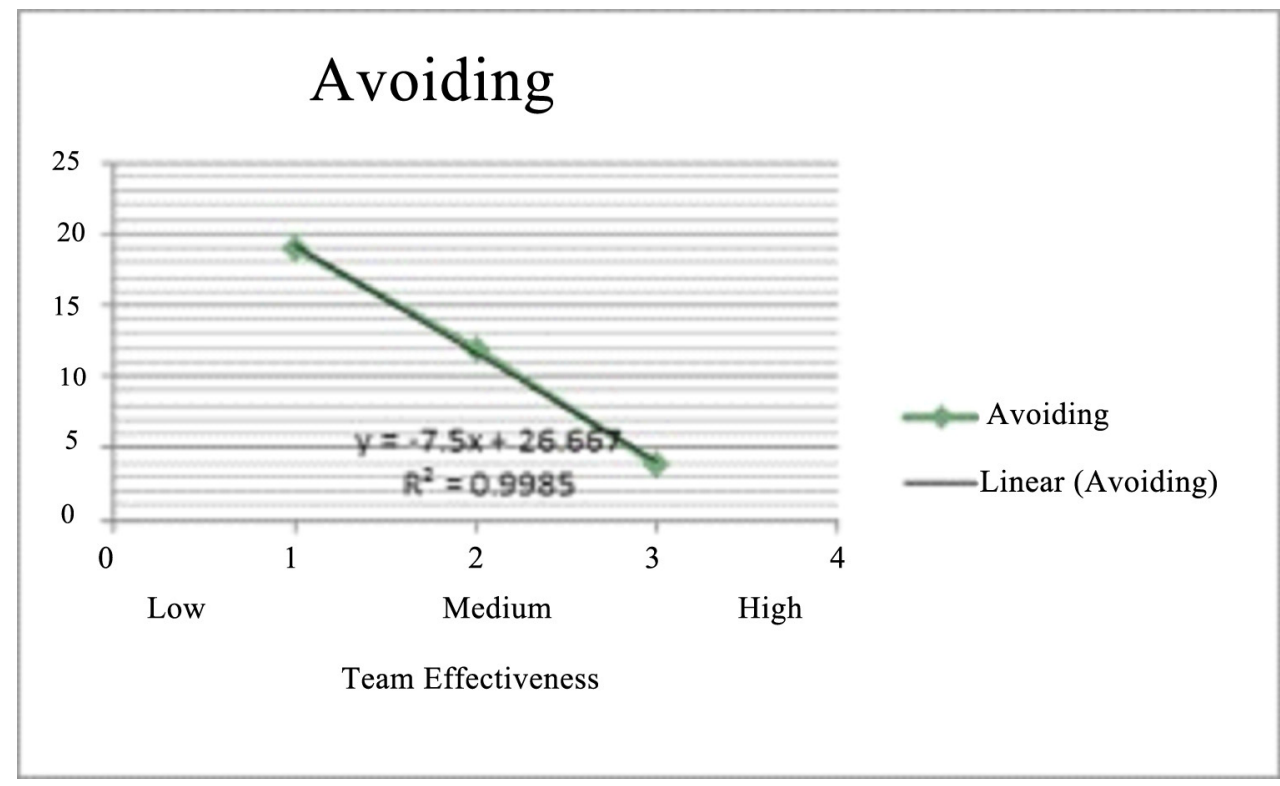

Figure 6. Avoiding Style and Team Effectiveness 